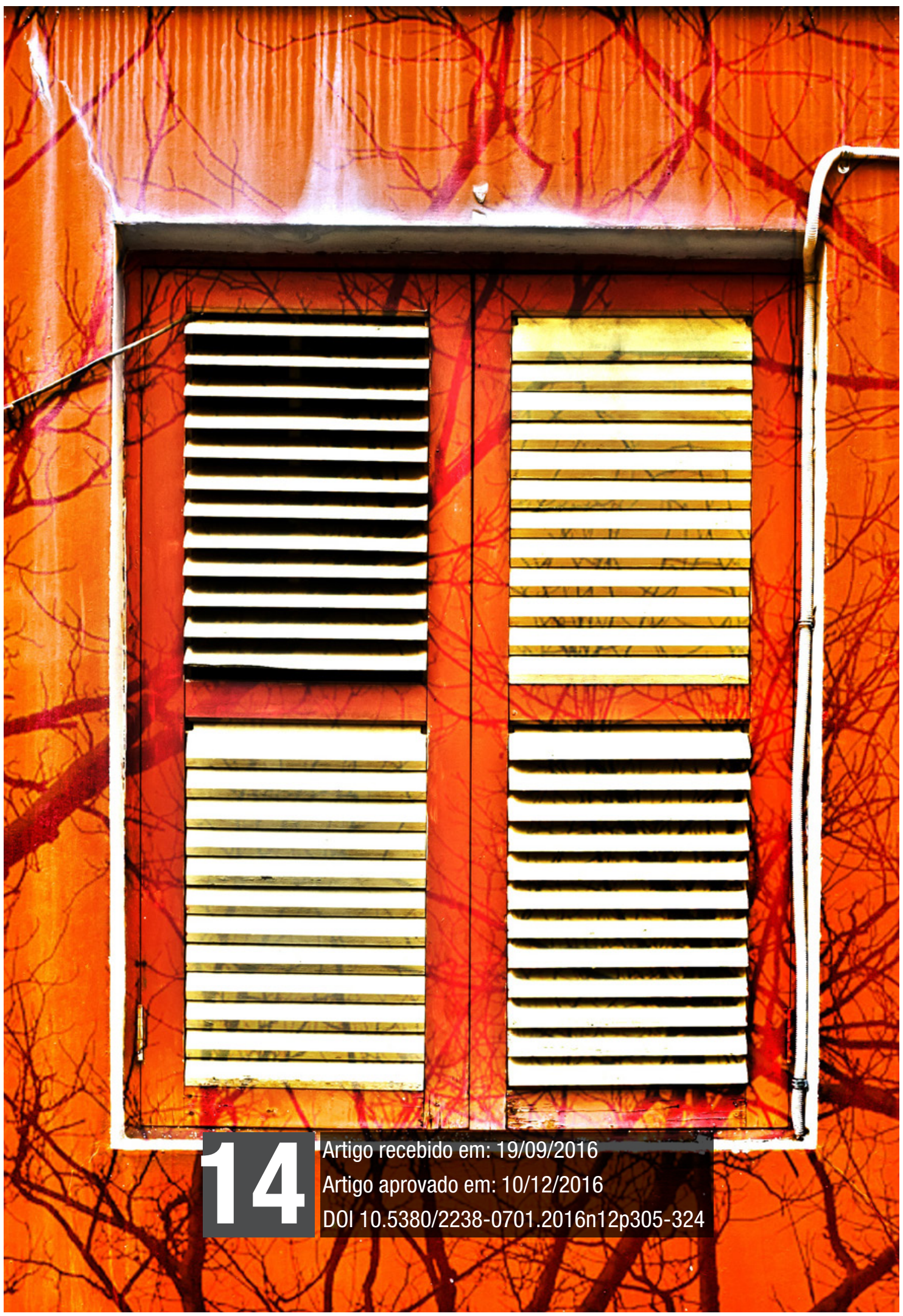


Hipertexto. Materiais didáticos. Educação a distância. 


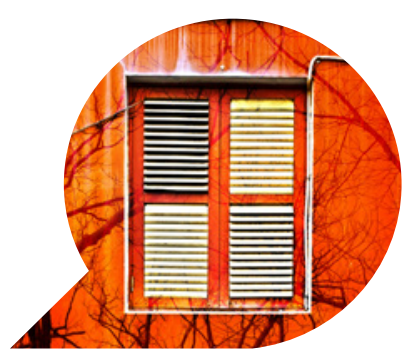

\title{
Materiais didáticos digitais na educação a distância: o uso do hipertexto como elemento interativo
}

\author{
Digital teaching materials in distance education: the use \\ of hypertext as interactive element
}

Materiales didácticos digitales en la educación a distancia:
el uso de hipertexto como elemento interactivo

HELENICE RAMIRES JAMUR ${ }^{1}$

GLAUCIA DA SILVA BRITO ${ }^{2}$

1 Doutoranda em Educação, na linha de Cultura, Escola, Ensino na UFPR, Grupo de Estudos Professor, Escola e Tecnologias da UFPR. Possui mestrado em Educação pela UFPR (2015). Graduada em Letras pela UFPR (2004). Possui especialização no Ensino de Língua Portuguesa e Literatura Brasileira pela UTFPR (2007). Graduada em Pedagogia pela Faculdade Dr. Leocádio José Correia (2010). Atuou como Supervisora de Projetos no Centro de Criação e Desenvolvimento Dialógico do Grupo Educacional Uninter em Curitiba. Tem experiência na área de Educação, com ênfase em Educação a Distância, Design Educacional, Materiais Didáticos para EaD. Atualmente é professora do Ensino Superior e coordenadora do Centro de Mediação Acadêmica no Centro Universitário Uninter.

2 Possui Graduação em Bacharelado e Licenciatura Português Inglês pela Faculdade de Educação Ciências e Letras de Cascavel (1990), Especialização na Metodologia do Ensino Tecnológico pela Universidade Tecnológica Federal do Paraná (1994), Mestrado em Tecnologia pela UTFPR (1997) e Doutorado em Linguística pela UFSC (2002). Atualmente é professora Associado I da UFPR. Tem experiência nas áreas de Educação e Comunicação, com ênfase em Tecnologias da Informação e Comunicação, atuando principalmente nos seguintes temas: Comunicação e tecnologias, tecnologias na educação, professor e as tecnologias de informação e comunicação, educação a distancia e formação do professor, inclusão digital. 
Resumo: Este estudo analisa o uso do hipertexto como forma de interação em materiais didáticos produzidos para a cursos na modalidade da Educação a Distância $(\mathrm{EaD})$. A problemática discutida pode ser resumida no seguinte: quais recursos hipertextuais devem ser considerados na produção dos materiais didáticos digitais? Considera-se o objetivo geral deste estudo o levantamento qualitativo quanto ao uso dos elementos hipertextuais em materiais didáticos digitais, produzidos para os cursos na modalidade de $\mathrm{EaD}$, como forma de interação. A metodologia utilizada foi de abordagem qualitativa, dividida em duas fases. A primeira fase foi um estudo exploratório e a segunda uma análise documental dos materiais de duas instituições. Os resultados apontam para o uso do hipertexto potencial e colaborativo, não se observou o uso do hipertexto cooperativo.

Palavras-chave: Hipertexto; Materiais didáticos; Educação a distância

Abstract: This study analyzes hypertext's use as an interaction form in teaching materials produced for distance educational courses. The issue discussed can be summarized as follows: which hypertext features should be considered in the production of digital learning materials? The aim of this study is the qualitative survey on the use of hypertext elements in digital learning materials produced to distance education courses, as a possibility of interaction. The methodology used was the qualitative approach, divided into two steps: exploratory study and document analysis. In the second step was made the documentary analysis of teaching materials available in the learning management system of the participating institutions, aiming the location and rating of hypertext elements in the materials. The results point to the use of the potential and collaborative hypertext, yet it was not observed the use of cooperative hypertext.

Keywords: Hypertext; Multimedia method; Educational technology

Resumen: Este estudio examina el uso de hipertexto como una forma de interacción en los materiales educativos producidos para los cursos en modalidad a distancia. Los temas tratados se 


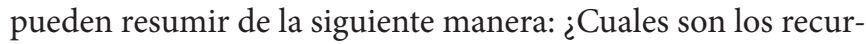
sos hipertextuales que debe ser considerados en la producción de materiales digitales para el aprendizaje? Se considera que el objetivo de este estudio es la encuesta cualitativa sobre el uso de elementos de hipertexto en los materiales de aprendizaje digitales producidos por los cursos en forma de educación a distancia como medio de interacción. La metodología utilizada fue un enfoque cualitativo, dividido en dos fases. La primera fase fue un estudio exploratorio y la segunda es un análisis documental de los dos materiales. Los resultados apuntan a la utilización del hipertexto potencial y de colaboración, no hubo uso de hipertexto colaborativo.

Palabras-clave: Hipertexto; Materiales didácticos; Educación a distancia. 


\section{Introdução}

Discutir a educação a distância como modalidade de ensino significa por vez ou outra esbarrar no tema do material didático ${ }^{3}$ e o seu papel na construção do conhecimento. Isso porque desde o surgimento da Educação a Distância (EaD), sua construção só foi possível por meio do material didático que deu apoio para o processo educativo de modo a se tornar ele mesmo o próprio curso.

Garcia Aretio (1994) contribui para essa argumentação dando um peso ainda maior para o material didático, na medida em que reconhece a sua relevância, a sua argumentação por si só justifica o estudo dessa temática sobre a qual nos debruçamos.

La elaboración de los materiales didácticos alcanza una especial complejidad porque sobre ellos se acumula la necesidad de reproducir las conductas del professor en el aula: deben motivar, informar, aclarar e adaptar las enseñanzas a los niveles de cada uno, dialogar, enlazar las experiencias del sujeto con las ensenãnzas, programar el trabajo individual o en equipo, y poner em juego la intuición, la actividad y aun la creatividad del alumno, aplicando los conocimientos a las situaciones medioambientales, a la vez que estabelecer un verdadero trabajo interdisciplinar (ARETIO, 1994, p. 177).

Embora o autor considere a produção de material impresso, o que se justifica pela época em que foi publicada sua obra, o mesmo trecho se encaixa perfeitamente neste estudo em que se observa o material didático preparado para o meio digital, o qual não deixa de buscar as características citadas.

Atualmente, com a inclusão das novas Tecnologias da Informação e Comunicação (TIC), o cenário da EaD passou por algumas mudanças. Dentre elas, as possibilidades de ação do indivíduo sobre o conteúdo que acessa, permitindo sua interação no processo educativo de forma ativa e cooperativa e, por isso, ressignificando o papel do aluno. Entendendo o material didático como elemento de mediação educativa na Educação a Distância, sob esse contexto de interações possíveis das tecnologias digitais, este estudo busca nos

3 Entendemos aqui o material didático como o conteúdo produzido nas mais variadas mídias e suportes, desde livros didáticos, videoaulas, diferentes vídeos, simuladores, games, materiais multimídia ou qualquer outra forma elaborada a ser disponibilizada ao estudante para o processo educativo. (JAMUR, 2015, p. 27) 
elementos hipertextuais as possiblidades de trabalho coletivo nessa modalidade de ensino.

Além de Landow (1997), Snyder (1997, 2010) que são autores clássicos ao se discutir o hipertexto e, ainda, observando os principais estudos que atualizaram o conceito de hipertexto no Brasil, sobretudo na área da linguística, como Gomes (2011) e Xavier (2009, 2002), percebe-se a opção por uma definição de hipertexto como um texto que permite diferente tipos de leitura não contínuas, culminando, portanto, com o conceito de texto digital utilizado em materiais didáticos da $\mathrm{EaD}$. Assim, olhando para os materiais digitais da $\mathrm{EaD}$, nesta investigação, formulamos uma questão central, sintetizada na seguinte problemática: Quais recursos hipertextuais devem ser considerados na produção dos materiais didáticos digitais?

Para responder a essa pergunta, considerou-se os materiais didáticos elaborados para o meio digital, ou seja, pensados e estruturados para serem acessados por dispositivos digitais, como PCs, tablets e outros dispositivos móveis, como os próprios smartphones, buscando refletir quanto ao papel dos elementos hipertextuais nesses materiais, investigando quais deveriam ser utilizados para a promoção de uma relação interativa do aluno com o material.

Nesse cenário, encontra-se algumas pesquisas sobre o tema, como o trabalho de Xavier (2009) que se insere na área da linguística, assim como outros pesquisadores que discutem especificamente o hipertexto. Além disso, é importante citar a tese de Gomes (2007) que apresenta significativas pistas para a classificação do hipertexto, apoiando a base teórica deste estudo. No entanto, percebe-se uma lacuna em relação às pesquisas que tenham como foco a produção de materiais didáticos para educação a distância, em especial aquelas que considerem a produção digital desses conteúdos, pensando nos usos do hipertexto.

Diante disso, o objetivo geral deste estudo foi o levantamento qualitativo em relação ao uso dos elementos hipertextuais em materiais didáticos digitais produzidos para os cursos na modalidade de $\mathrm{EaD}$ como forma de interação, buscou-se compreender como tem sido trabalhado o hipertexto diante de uma classificação já estabelecida por Primo (2003a), que evidencia as possibilidades de coautoria criadas por essa forma de apresentação do conteúdo. Os objetivos específicos foram analisar os materiais didáticos digitais quanto ao 
uso de recursos hipertextuais, organizar a classificação de elementos hipertextuais a partir de discussões teóricas, resultando em um último objetivo específico que foi a elaboração de guia com orientações básicas para a produção didática para o meio digital.

\section{Fundamentação teórica}

Considerando a caminhada da $\mathrm{EaD}$ até o momento, é possível verificar mudanças significativas, isso acontece tanto nos processos de mediação da aprendizagem quanto na atual popularidade da modalidade. A cada geração, novas tecnologias vão surgindo e permitindo a utilização de mais recursos. No entanto, é inegável que, com as tecnologias intelectuais em uso no momento, a $\mathrm{EaD}$ foi amplamente beneficiada no que tange à interação, interatividade e, especialmente, na possibilidade de cooperação.

Lévy (2010, p. 151-152) defende que a internet é um mundo virtual que permite a inteligência coletiva, já que a interatividade entre os participantes/usuários é intensa e possível. O autor apresenta a ideia de que a linguagem passa a ter novo sentido na cibercultura, de modo que o texto, seja ele alfabético, iconográfico ou visual, passa a ser dinâmico, possibilitando caminhos diferentes a serem percorridos pelo leitor individualmente. A educação, por isso, conta com uma nova forma de comunicação, na qual diferentes recursos dão um novo rumo a ser seguido pela educação a distância, que tem à disposição diferentes tecnologias para se produzir materiais didáticos digitais, proporcionando novas formas de ensinar e aprender.

Diante desse cenário, o material didático passou a ser acessado em plataformas virtuais e, por isso, teve de ser adaptado, extrapolando os limites do texto escrito, em alguns casos, elaborado para o meio digital e contando com diferentes recursos gráficos e audiovisuais. Dessa forma, o planejamento de cursos a distância se configura como uma etapa fundamental para o processo, já que a forma com que os recursos serão apresentados deve ser amplamente discutida e planejada.

Assim, busca-se, no estudo aqui relatado, uma atualização dos conceitos de hipertexto diante das novas tecnologias digitais e sua relação com o processo de interação, como sustentação teórica para a resposta da problemática de pesquisa anteriormente referida. 


\section{Conceito de interatividade no contexto da pesquisa}

Considerando que o processo comunicativo é central para a construção do conhecimento, percebe-se que o material didático é o recurso fundamental para que o processo educativo seja possível na $\mathrm{EaD}$, afinal a comunicação entre professores e alunos se dá por meio dele. Para além dos conceitos de colaboração que a interatividade pode trazer, a web $2.0^{4}$ permite a cooperação que seria uma participação efetiva na construção coletiva.

Nessa abordagem, o referencial teórico discutido neste estudo, apresenta os diferentes pontos de vista em relação à interatividade, deparando-se com a visão de Primo (2011) que tece críticas à grande parte das conceituações já descritas por McLuhan (1969), Thompson (1998), Rafaeli (1988), especialmente por salientarem ora uma visão tecnicista, ora transmissionista do termo e até mesmo mercadológica, quando enfatizam os equipamentos e softwares, os argumentos de venda e pouco as relações humanas.

Diante disso, neste estudo concorda-se com ponto de vista sociológico da pesquisadora brasileira Belloni (2006) que entende tal interação cuja principal característica seria a troca entre os atores do processo com caráter "socioafetivo", "diferente do processo interativo, que é mera troca de informações”. No entanto, a autora reforça que ambas podem e devem promover a aprendizagem e se fazem necessárias e importantes para a $\mathrm{EaD}$ de forma complementar uma à outra (JAMUR, 2015, p. 39).

Consideramos, portanto, que no material didático, ao contrário de visões rígidas como de Silva (2010) que estipula regras tão rigorosas a ponto de desconsiderar o hipertexto como interativo, os links, as fontes de pesquisas indicadas pelo professor e a linguagem por ele utilizada, na pesquisa aqui relatada, podem ser consideradas interativas, aceitando uma variação qualitativa entre uma ou outra forma de interagir, como a escala de interatividade elaborada por Pinto e Leitão (2013), mas que não deixam de ser formas de interagir.

4 A Web 2.0 é a segunda geração de serviços online e caracteriza-se por potencializar as formas de publicação, compartilhamento e organização de informações, além de ampliar os espaços para a interação entre os participantes do processo. (PRIMO, 2007) 


\section{Atualizando o conceito de hipertexto}

O hipertexto tem origem anterior à criação da internet. Theodore Nelson o descreveu em 1960 em seu trabalho de conclusão de curso na Universidade de Harvard, depois dele podemos citar os trabalhos mais recentes de Lévy (2010), Vannevar Bush (citado por GOMES, 2011, p. 17) e outros que vinculam o termo a um novo padrão de comunicação.

Castells (2003, p. 165), no entanto, apresenta uma importante discussão colocando em xeque até mesmo a existência de um hipertexto, no ponto de vista do autor, criou-se uma visão muito material do termo, ao passo que o hipertexto estaria presente como uma manifestação cultural e que pode coexistir em diferentes formas, mas especialmente dentro do indivíduo e não fora. $\mathrm{O}$ autor ressalta que tal limitação provavelmente irá permanecer já que a ótica capitalista amarra e comercializa espaços e banda da rede, tratando como mercadoria, tornando hipertexto como algo modesto dentro do possível pelas condições culturais.

No Brasil, as pesquisas sobre o hipertexto se dividem entre aquelas que trazem o termo dentro de investigações no campo da informática, outras da Comunicação, mas sobremaneira na área da Linguística é possível verificar um aprofundamento na concepção, sem relacionar necessariamente com a tecnologia. Entretanto, encontramos em Gomes (2011, p. 150) a argumentação de que o hipertexto seria exclusivamente virtual, já que, para o autor, a presença de links é que seria a atributo principal desse texto.

O hipertexto pode ser entendido como um texto exclusivamente virtual que possui como elemento central a presença de links. Esses links, que podem ser palavras, imagens, ícones etc., remetem o leitor a outros textos, permitindo percursos diferentes de leitura e de construção de sentidos a partir do que for acessado e, consequentemente, pressupõe certa autonomia de escolha dos textos a serem alcançados através dos links. (GOMES, 2011, p. 15).

Já Xavier (apud Marcuschi e Xavier, 2010, p. 208) define o hipertexto como "forma híbrida, dinâmica e flexível de linguagem que dialoga com outras interfaces semióticas, adiciona e acondiciona à sua superfície formas outras de textualidade", ou seja, independentemente de ser digital ou não. 
Para o estudo em materiais didáticos para $\mathrm{EaD}$ produzidos para o meio digital, convém fazer uso da definição que apoia o ponto de vista de Nelson, citado por Gomes (2011, p. 20) para quem o hipertexto é "um texto verbal ou pictórico interconectado com inúmeros outros trechos, por meio de links, de forma complexa, isto é, não linear, que não pode ser representado de modo conveniente de forma impressa”.

Silva (2010, p. 17) soma essa discussão quando afirma que o "usuário" ao fazer uso de tecnologias hipertextuais teria diante de si a possibilidade de "interferir, modificar, produzir e compartilhar" construindo uma forma de diálogo do qual depende a própria criação dos textos. O autor reforça que o hipertexto possibilita uma nova forma de leitura na qual é preciso manter-se atento para o que está escrito, mas sem perder de vista o que é mostrado e comentado também, desse modo, saindo do modelo, segundo o autor, "simplificador em que emissão está separada de recepção, mas abrindo a perspectiva para um pensamento complexo" (SILVA, 2010, p. 9).

Apresentada a concepção do termo, se faz necessária a reflexão de que mesmo no formato digital, o hipertexto tem características que promovem diferentes formas de navegação. Como possibilidade de classificação, Primo (2003a, p. 9 - 15) propõe três tipos de hipertexto, conforme sua interação. Chama de hipertexto potencial: "este tipo de hipertexto, onde os caminhos e movimentos possíveis estão pré-definidos e que não abrem espaço para o interagente visitante incluir seus próprios textos e imagens.", o hipertexto colaborativo define como "aqueles que se cadastram no site e modificam as imagens produzidas anteriormente por outro artista envolvem-se em um hipertexto. A colaboração constitui-se em uma colagem, sem discussões durante o processo criativo". Detalhando a explicação quanto à essa classificação de hipertexto, o autor acrescenta:

Enquanto no hipertexto potencial apenas o leitor se modifica, permanecendo o produto digital com suas características originais, no hipertexto cooperativo todos os envolvidos compartilham a invenção do texto comum, à medida que exercem e recebem impacto do grupo, do relacionamento que constroem e do próprio produto criativo em andamento. Já o hipertexto colaborativo constitui uma atividade de escrita coletiva, mas demanda mais um trabalho de administração e reunião das partes criadas em separado do que um processo de debate (nesses casos, inclusive, uma única pessoa pode assumir as decisões do que publicar) (PRIMO, 2003a, p.15). 
Portanto, classificaremos aqui como hipertexto cooperativo aquele que oferece possibilidades de criação coletiva, chamando para uma discussão contínua que modifica o material didático à medida em que é desenvolvido. Diferentemente da colagem colaborativa, o hipertexto cooperativo depende do debate (PRIMO, 2003a).

A classificação do autor citado, culmina com a abordagem de interatividade assumida neste estudo e, por essa razão, foi utilizada na análise dos dados da pesquisa aqui apresentada, já que os tipos de hipertexto sugeridos por Primo (2003a) são abrangentes o suficiente para que as mais variadas formas de hipertexto sejam consideradas.

\section{A relação entre o hipertexto e a interatividade}

Após o levantamento dos principais conceitos nos quais se baseou este estudo, se faz necessário responder um questionamento inevitável que, embora aparentemente tenha sido mencionado nas conceituações, se considerou pertinente como elemento norteador: Afinal, qual a relação entre interatividade e hipertexto? Para responder a esta pergunta buscamos em Freire (1996) o início da argumentação. Na obra Pedagogia da autonomia (1996) o autor faz críticas aos principais modelos de ensino que privilegiam a transmissão de saberes, que ele chamou de "educação bancária".

Trazendo a concepção para a educação a distância, discute-se a busca por materiais didáticos que promovam uma educação significativa, ativa, instigando o aluno na busca do conhecimento. Para isso, é preciso pensar o material, ao lado da tutoria, como elemento mediador da educação a distância e dessa lógica decorre a necessidade de pensar a interatividade como ponto principal deste processo.

As novas tecnologias da informação e comunicação proporcionam a esse material a mudança do meio impresso para o meio digital, adaptando o formato e recursos.

Diante desse raciocínio, entende-se que o hipertexto encontra no meio digital a sua concretização, isso porque a construção de um material didático digital permite os mais variados recursos que levam o usuário (aluno) a interagir com o conteúdo de forma mais ou menos amplas, conforme o formato disponível. Para isso, o hipertexto deve ser "tratado com reflexão por quem produz materiais digitais, de maneira a encontrar um aliado no processo educativo e não a reprodu- 
ção dos modelos focados em "transmissão de conteúdos" na forma de treinamentos e design instrucional" (JAMUR, 2015, p. 54).

Além disso, os materiais que são pensados considerando a participação do aluno, contribuem para modificar o pensamento de que o professor seria o titular do conhecimento, criando possibilidades de interação. Ferreira (2008) argumenta em termos próximos, propondo reflexão quanto à própria ação educativa:

Se comunicar não é apenas transmitir e aprender não é só receber, então, é indispensável pensar a ação educativa como um processo no qual os sujeitos se engajam em relação dinâmica (prática pedagógica) e transformadora (aprendizagem). Isso não significa descartar a priori todas as práticas pedagógicas baseadas no paradigma estímulo-resposta, mas sim avançar para além dele, com ele concorrentemente (FERREIRA, 2008, p. 85).

O hipertexto que é cerne deste estudo representa uma possibilidade latente de contribuição para os cursos a distância da atualidade, mas é preciso reforçar que nada pode ser feito sem um projeto pedagógico consistente e vivo, fundamental para a prática pedagógica, independente da modalidade de ensino.

O formato digital extrapola as possibilidades dos materiais impressos na modalidade da EaD. Enquanto no material impresso há um convite à reflexão, o material digital permite a produção e contribuição da reflexão no próprio material (desde que postado no ambiente virtual), além disso, o hipertexto (forma de navegação não linear oportunizada por meio de links) também apresenta a possibilidade de retomada de qualquer conteúdo (desde que previamente planejado pelo professor) considerando as particularidades de conhecimentos de cada aluno.

\section{Metodologia}

$\mathrm{Na}$ busca por um segundo olhar para o hipertexto, buscou-se responder ao seguinte questionamento: quais elementos hipertextuais devem ser considerados na produção de materiais didáticos para a EaD?

Para tanto, tomou-se como ponto de partida a formulação de hipóteses decorrentes de observações prévias durante a prática profissional na função de supervisão pedagógica de produções didáticas 
para $\mathrm{EaD}$ somadas à pesquisa bibliográfica e discussões sobre o tema. Elaborou-se as seguintes proposições:

a) Embora alguns materiais sejam elaborados para o meio digital, fazendo uso de recursos hipertextuais, são escassas as produções que consideram o hipertexto cooperativo, que permitem a relação do estudante com o conteúdo, possibilitando postagens e comentários, interagindo além da escolha do próprio percurso.

b) As equipes de trabalho que produzem o material didático para $\mathrm{EaD}$ carecem de orientações para propor adequadamente os recursos hipertextuais mais interativos. (JAMUR, 2015, p. 59)

De caráter qualitativo, a investigação dividiu-se em duas fases: estudo exploratório e análise documental. A primeira fase, estudo exploratório, objetivou a busca por instituições de ensino potencialmente produtoras de materiais didáticos digitais estruturados dentro dos conceitos de interatividade e colaboração.

Como instrumento de coleta de dados foi elaborado um questionário, elencando cinco questões objetivas e duas questões discursivas para que o participante discorresse livremente sobre a composição da sua equipe de produção e o formato do material.

Para responder ao questionário foram escolhidas 10 instituições de ensino superior brasileiras, dentre públicas e privadas, que oferecem cursos a distância. O critério para a escolha partiu do contato já estabelecido profissionalmente com as instituições e, ainda, o perfil compatível com o potencial de produtoras de materiais didáticos digitais, uma vez que para isso entende-se a necessidade de um mínimo de estrutura disponível.

A aplicação do questionário se deu por meio da plataforma do Google docs, essa opção vem do fato de que as instituições estão dispersas geograficamente, impossibilitando o contato pessoalmente. Iniciou-se o contato via e-mail e em seguida foi feito o envio do link com o questionário eletrônico. As questões foram elaboradas com o intuito de se levantar as informações básicas quanto à produção dos materiais didáticos para se obter um cenário em relação à equipe, formas de disponibilização do material, tipos de arquivos gerados. Do cruzamento desses dados foi possível coletar evidências quanto ao potencial das instituições para a aplicação da segunda fase da pes- 
quisa. Apenas 6 instituições responderam ao questionário, para o sumário das respostas, devido ao sigilo das informações, foram nomeadas com letras de A até $\mathrm{F}$, na ordem com que se recebeu as respostas.

Para a segunda fase da pesquisa, foi necessária a análise documental dos materiais didáticos produzidos para a educação a distância. As duas instituições de ensino a distância que fizeram parte desta etapa, mantiveram a denominação A e F original da primeira fase.

Os documentos estudados foram os materiais didáticos em arquivos digitais disponibilizados no Ambiente Virtual de Aprendizagem. Cada instituição ficou livre para definir o documento que seria disponibilizado pois entendeu-se como irrelevante a comparação entre áreas do conhecimento e necessário deixar a critério da instituição tal escolha sob pena de não se ter documento para investigar, pensando que as escolhas seriam por aqueles materiais melhores avaliados na visão de cada instituição.

\section{Análise dos dados}

$\mathrm{Na}$ análise dos dados a instituição $\mathrm{F}$ foi excluída pela resposta que deu à sexta questão informando que disponibiliza o material em CD ou DVD, o que dificulta a análise proposta, uma vez que, fora do ambiente virtual de aprendizagem não haveria como propor cooperação na construção do material que está fora de uma plataforma digital. Também foi descartada a instituição E que afirmou oferecer o material somente em arquivo pdf e nenhum material digital.

Restaram quatro instituições para a segunda fase (A, B, C e D), foi realizado contato telefônico e via e-mail solicitando acesso a um dos materiais produzidos, postado no ambiente virtual de aprendizagem, para realização da análise. No entanto, a instituição B, mesmo recebendo a informação de que seriam dados sigilosos, recusou-se a liberar o material justificando que teria direito autoral envolvido e, por isso, não poderia receber críticas. Além disso, a instituição C passou por conflitos internos que suspenderam temporariamente a oferta da $\mathrm{EaD}$, sendo impossibilitada de participar da segunda fase. O resultado da Fase 1 pode ser resumido no seguinte quadro: 


\begin{tabular}{|c|l|}
\hline Instituição & Resumo dos resultados \\
\hline A & Liberou acesso aos materiais didáticos \\
\hline B & Não liberou o acesso aos materiais \\
\hline C & Oferta de cursos suspensa \\
\hline D & Liberou acesso aos materiais didáticos \\
\hline E & O mesmo material impresso é digitalizado \\
\hline F & Material enviado em CD ou DVD \\
\hline
\end{tabular}

Quadro 5 - Resumo dos resultados da fase exploratória Fonte: elaborado pela autora

Portanto, a segunda fase na qual se realizou a análise documental, participaram somente as instituições A e D. Durante a análise dos recursos hipertextuais utilizados, classificou-se os tipos de hipertexto presentes em cada material, seguindo a abordagem de Primo (2003) já detalhada anteriormente: hipertexto potencial, colaborativo e cooperativo.

Partindo para a síntese do que foi observado empiricamente nesta pesquisa, ressaltamos o material da instituição A que apresentou uma estrutura hipertextual linear, representada pela passagem de telas. No entanto, as leituras dessas telas expandem para outras leituras e recursos que levam o leitor para caminhos diferentes, sendo o uso do hipertexto potencial o recurso mais encontrado, ao passo que não foi localizado nenhum processo de coautoria nos referidos materiais, isto é, não apresentou casos do que Primo considera como hipertexto cooperativo.

Os elementos de construção coletiva e interatividade dos cursos analisados dessa instituição ficam inteiramente a cargo do ambiente virtual de aprendizagem, por meio de chats e fóruns é que os alunos podem apresentar seu ponto de vista e contribuição, no entanto, no material didático não há um espaço aberto para isso, nem mesmo direcionando para chats, fóruns ou wikis, que seriam recursos possíveis em ambientes virtuais para tal feito (JAMUR, 2015, p. 79).

O material que foi analisado da instituição D apresenta estrutura linear, trata-se de um arquivo construído como um livro pronto para impressão, no entanto, a linguagem e os recursos disponíveis no material levam ao modelo de hipertexto potencial e colaborativo, mas novamente ausente de hipertexto cooperativo, tampouco considera 
a coautoria. $\mathrm{O}$ ambiente virtual é que apresenta ferramentas para a discussão em grupo, como fóruns, mas não é uma participação do aluno na construção do material que possibilita somente navegação linear, página a página, como em um livro didático impresso.

Ficou evidente a carência de propostas cooperativas nos materiais analisados, mas durante conversas informais com profissionais da instituição A, houve o entendimento das limitações do próprio $\mathrm{LMS}^{5}$ que deveria armazenar as contribuições dos alunos e, por ter um número grande de cursos e alunos, até mesmo a mediação dessa proposta ficaria comprometida, observando a questão sustentável do próprio projeto de EaD. No entanto, a velocidade com que se avançam as pesquisas em tecnologia apontam-se resoluções dessa questão de espaço de armazenagem que estaria fora do âmbito desta análise, cujo foco está no processo de ensinar e aprender a distância que na prática pode ser enriquecido com as possibilidades de interação.

\section{Considerações Finais}

Diante dos resultados dessa investigação percebe-se a necessidade de se pensar criticamente na produção do material didático, de maneira a acompanhar as possibilidades que o meio digital pode permitir. É importante salientar que não se trata de meramente seguir uma "moda" ou "tendência" para essa produção, mas de se explorar largamente os recursos que irão contribuir para um fazer educativo significativo, no qual o aluno possa, de fato, ser sujeito do processo, interferindo no percurso da construção coletiva, dentro de um conceito de coautoria.

No entanto, sabe-se que, além de mudança na forma de se conceber e estruturar o material, encontram-se limitações técnicas para tal produção hipertextual cooperativa. Hoje, equipes especializadas para produção de materiais no Brasil têm sido preparadas na prática, isso porque a mudança e atualização de linguagens de programação, conceitos de design e até mesmo de planejamento didático acontecem de forma acelerada, resultando formações acadêmicas desatualizadas.

5 Learning Management Systems: termo utilizado para fazer referência ao Sistema de Gestão da Aprendizagem, local onde está inserido o Ambiente Virtual de Aprendizagem e outros sistemas de gestão acadêmica utilizados pela equipe que atua na EaD. 
Além disso, muitos cursos a distância atendem quantidades consideráveis de alunos, de modo que, ainda que estivessem materiais disponíveis para coautoria, seria preciso um espaço de armazenamento muitas vezes inviável para as instituições. Os professores que produzem o material também precisam de formação específica para que sua produção considere tais elementos, contudo, para isso será necessária uma mudança de mentalidade, da forma com que se entende a escrita coletiva, descentralizando o foco no docente como transmissor de saberes e propondo uma visão cooperativa, na qual o processo fica mais evidente que o próprio conteúdo, numa concepção de aprender a aprender.

Portanto, buscando colocar luz nesse tema, este estudo sugere que se pense o material para o meio digital, buscando os recursos e técnicas que possibilitem a participação ativa dos alunos, saindo da lógica transmissionista ainda tão latente no ensino como um todo.

\section{REFERÊNCIAS}

ARETIO, L G. Educación a distancia hoy. Madrid: Libreria UNED. 1994.

JAMUR. H. R. O uso do hipertexto como forma de interação na Educação a Distância. Dissertação (Mestrado em Educação) Programa de Pós-graduação em Educação. UFPR: Curitiba, PR. 2015.

BELLONI, M. L. Educação a distância no Brasil. Instituto de Pesquisas avançadas em educação. São Paulo: Autores Associados. 2007.

CASTELLS, M. A Galáxia da Internet: reflexões sobre a internet, os negócios e a sociedade. Tradução: Maria Luiza X. de A. Borges; revisão Paulo Vaz. - Rio de Janeiro: Zahar. 2003.

COSTA, M. L. F. org. Educação a distância no Brasil: avanços e perspectivas. Maringá: Eduem, 2013.

FERREIRA, R. Interatividade educativa em meios digitais: uma visão pedagógica. Tese (doutorado em educação). Instituição de ensino: Unicamp. Campinas, SP, 2008.

FREIRE, P. Pedagogia da autonomia: saberes necessários à prática educativa. São Paulo: Paz e Terra, 1996. 
GOMES, L. F. Hipertexto no Cotidiano Escolar. 1ª ed. São Paulo: Cortez, 2001.

. Hipertextos multimodais: o percurso de apropriação de uma modalidade com fins pedagógicos. 2007, 212 fl. Tese (doutorado em Linguística). Instituto de estudos da linguagem. Unicamp. Campinas, SP.

LANDOW, G. Hypertext: the Convergence of Contemporary Critical Theory and Technology. Baltimore: Johns Hopkins University Press, 1997.

LÉVY, P. Cibercultura. São Paulo: Editora 34, 2010.

MACHADO, A. Pré-cinemas e pós-cinemas. Campinas: Papirus, 1997.

MARCUSCHI, L. A. XAVIER, A. C. Hipertexto e Gêneros Digitais. 3. edição. São Paulo: Cortez, 2010.

MCLUHAN, M. Os meios de comunicação como extensões do homem. São Paulo: Cultrix, 1969.

PRIMO, A. Quão interativo é o hipertexto? Da interface potencial à escrita coletiva. Fronteiras: Estudos Midiáticos. São Leopoldo, v. 5, n. 2, p. 125-142, 2003a.

Interação Mediada por computador: a comunicação e a educação a distância segundo uma perspectiva sistêmico-relacional. Tese de doutorado. UFRGS, 2003b.

Interação mediada por computador: comunicação, cibercultura, cognição. 3. ed. Porto Alegre: Sulina, 2011.

O aspecto relacional das interações na Web 2.0. E-Compós, Vol. 9, 2007.

PINTO, A. C. LEITÃO, U. A. Interatividade e transposição didática com recursos do moodle: uma proposta de critérios de análise. Rev. Teoria e Prática da Educação, v. 16, n. 1, p. 57-70, Janeiro/Abril 2013.

RAFAELI, S. Interactivity: From new media to communication, Sage Annual Review of Communication Research: Advancing Communication Science Vol. 16 p. 110-134, Sage: Beverly Hills, CA, 1988.

SILVA, M. Sala de aula interativa: educação, comunicação, mídia clássica. 5 . ed. São Paulo: Loyola, 2010. 
SNYDER, I. Hypertext: the eletronic labyrinth. Washington: New York University Press, 1997.

Then, now, next: hypertext, literacy and chang. Belo Horizonte: Educ. rev. vol.26 no. $3,2010$.

THOMPSON, J. B. A mídia e a modernidade: uma teoria social da mídia. Petrópolis: Vozes, 1998.

XAVIER, A. C. A era do hipertexto. Recife: UEPE, 2009.

O hipertexto na sociedade da informação: a constituição do modo de enunciação digital. 2002. Tese (doutorado em linguística) - Instituto de Estudos da Linguagem, Unicamp, Campinas, 2002. 